Research Article

\title{
Collaborative Mining Sequence Optimization for Multiple Stopes under Intensive Mining
}

\author{
Long Zhang $\mathbb{D}^{1},{ }^{1}$ Jianhua Hu $\mathbb{D}^{2},{ }^{2}$ Xinzhong Wang, ${ }^{1}$ Xiuwei Chai, ${ }^{3}$ and Lei Zhao ${ }^{4}$ \\ ${ }^{1}$ State Key Laboratory of Hydraulics and Mountain River Engineering, College of Water Resource \& Hydropower, \\ Sichuan University, Chengdu 610065, China \\ ${ }^{2}$ School of Resources and Safety Engineering, Central South University, Changsha 410083, China \\ ${ }^{3}$ School of Resources and Safety Engineering, Wuhan Institute of Technology, Wuhan 430074, China \\ ${ }^{4}$ Hubei Sanning Mining Co. Ltd, Yichang 443100, Hubei, China
}

Correspondence should be addressed to Jianhua Hu; hujh21@126.com

Received 25 December 2020; Revised 12 March 2021; Accepted 20 March 2021; Published 1 April 2021

Academic Editor: Lijie Guo

Copyright (C) 2021 Long Zhang et al. This is an open access article distributed under the Creative Commons Attribution License, which permits unrestricted use, distribution, and reproduction in any medium, provided the original work is properly cited.

\begin{abstract}
The optimization of a mining sequence not only reduces stress concentration in surrounding rock but also prevents underground debris flows, significantly improving safety. Firstly, the $870-898 \mathrm{~m}$ level of the eastern mining area in the Tiaoshuihe phosphate mine was divided into 25 ore blocks, and six different mining sequences were designed for this area. Then, it was calculated that five ore blocks must be processed simultaneously to reach the annual production output. The distances between the five simultaneously mined ore blocks will inevitably affect the efficiency of the equipment for any scheme. So, a collaborative model considering both the area stability and production capacity was established by combining the distance between the centers of the five ore blocks as an index. Differences in stability, deformation, and plastic zone size between the schemes are compared. The calculation results show that a mining scheme with a convex stepped shape produces the best results. These results provide a general method for entropy-based mining sequence optimization and an optimal solution for the Tiaoshuihe phosphate mine.
\end{abstract}

\section{Introduction}

Filling mining is a popular contemporary technique that is increasingly advocated by many governments. Ground pressure in these types of mines will increase considerably as mining continues to deeper depths, so the corresponding requirements for ground pressure control will continue to expand $[1,2]$. If measures are only taken after ground pressure triggers surrounding rock damage, production costs will increase and the production efficiency will be reduced. To better compensate for ground pressure, active control must be used instead of passive control. Implementing a reasonable mining sequence is an active ground pressure control method [3].

In 1963, Goodman and Brown put forward the concept of rock engineering excavation steps, which is described as the mining sequence now [4]. In 1972, Zouanalyzed the influence of construction steps on the construction of underground tunnels and proposed the concept of simulated excavation steps for the first time but did not combine finite element calculations and simulations [5]. Liu successfully optimized the mining sequence of the Dongguashan deep well by considering the production capacity, stress, displacement, and plastic zone of the surrounding rock [6]. Kang simulated different mining sequences in the middle level of the Xinli mining area of Sanshandao Gold Mine, obtaining characteristic values of the stress and displacement of rock under different mining steps. This work suggested that it is safe and efficient to mine one panel at the interval of two panels [7]. Based on the time-varying evolution of the mechanical parameters of a rock mass, $\mathrm{Hu}$ designed five mining sequence schemes in the deep section of the Gaofeng mine. Using FLAC3D, the spatiotemporal evolutions of rock mass mechanical parameters were simulated under different mining sequences. The results show that case 2 represents the best mining sequence [8]. 
The Tiaoshuihe phosphate mine is a gently inclined thin ore body with an average thickness of $3.22 \mathrm{~m}$. This mine contains a mining area of approximately $23.42 \mathrm{~km}^{2}$ and an estimated reserve of 200 million $\mathrm{t}[9,10]$. To realize production, it is necessary to plan intensive mining, adjust the mining areas of simultaneous production in one location, and then maximize the utilization rate of personnel and equipment [11]. At present, excavating is mainly concentrated in the 870-898 $\mathrm{m}$ level of the eastern mining area. Optimization of the mining sequence in this area is necessary by considering regional stability and productivity objectives [12].

\section{Geological Characteristics of Mining Area}

Tiaoshuihe phosphate mining area is located in the north margin of Huangling fault area. The strata are inclined to NNE monoclinic structure. The dip angle is generally $4-8^{\circ}$. The attitude of the stratum becomes steep due to the influence of fault structure. There are 6 faults in the mining area, and all faults are normal. Among them, F1 and F4 are NNW trending faults. F3, F5, and F6 are NW trending faults, and F2 is the NNE trending fault. F1 is the eastern natural boundary of the mining area. F5 is the southern natural boundary of the mining area. The F4 fault divides the mining area into two natural blocks, the east and the west. It causes great damage to the continuity of the ore body. The model of ore body is shown in Figure 1.

$870-898 \mathrm{~m}$ level is the main research area. $870-898 \mathrm{~m}$ level belongs to the main industrial phosphate bed, which is stable and widely developed. It is distributed at the bottom of Huji member and occurs in layers. The roof is thin to middle micritic dolomite in the lower submember of Huji member, intercalated with thin layer of gray (weathering color is grayish yellow) micritic mudstone. And the floor is thick bedded siliceous block in the upper submember of Zhangcunping member. The average thickness of $870-898 \mathrm{~m}$ level is $4.61 \mathrm{~m}$. The grade of $\mathrm{P}_{2} \mathrm{O}_{5}$ is $21.22-34.02 \%$, and the average is $27.21 \%$.

\section{Model Construction and Scheme Design}

3.1. Model Construction. In Figure 2, the ore body was meshed by using a DIMINE-CAD-MIDAS/GTS coupling operation and then imported into the numerical simulation software FLAC3D for calculation. The fractures in the 870-898 $\mathrm{m}$ level of the eastern mining area are relatively developed, and the mining sequence is related to the overall stability and mining safety of the area [9]. According to geological occurrence conditions, a three-dimensional ore body model was established, and 25 numbered mining areas were identified. The width of each mining area was $60 \mathrm{~m}$, and the length was $100 \mathrm{~m}$. According to Saint-Venant's principle, an area 3 times greater than the ore body was selected to determine the model boundary $[13,14]$.

3.2. Scheme Design. Six schemes of mining sequences were designed for optimization. To ensure the comparability of the six schemes, all schemes completely mined and filled the
25 mining areas. Each scheme includes 50 calculation steps to simulate the process of mining and filling. Then, the displacement, stress, and plastic zone results were analyzed.

The six mining sequence schemes are shown in Figure 3. The numbers in the table indicate the mining sequence: scheme 1 mines along the short axis of the mining area, from east to west; scheme 2 mines along the long axis of the mining area, from south to north; scheme 3 mines from southwest to northeast; scheme 4 mines from northeast to southwest; scheme 5 mines northward a convex stepped shape; and scheme 6 mines in a "V" shape.

Numerical simulation of the mining area requires a mathematical model of the rock mechanical properties, which is usually the defined stress-strain relationship [15]. According to a geological investigation at the Tiaoshuihe phosphate mine and laboratory mechanical experimentation, the initial stress is considered to reflect only the selfweight of the rock mass. The Mohr-Coulomb constitutive model is commonly used, as follows [16]:

$$
\sigma_{1}=\frac{1+\sin \varphi}{1-\sin \varphi} \cdot \sigma_{3}+\frac{2 c \cdot \cos \varphi}{1-\sin \varphi}
$$

where $c$ is the cohesion in $\mathrm{MPa}, \sigma_{1}$ and $\sigma_{3}$ are the principal stresses in $\mathrm{MPa}$, and $\varphi$ is the internal friction angle, .

\section{Results}

Six command flows were compiled according to the mining sequence schemes described above [17]. Combined with the rock mass mechanical parameters in Table 1, the aforementioned three-dimensional ore body grid model was imported into the finite element numerical simulation software, FLAC3D. The maximum displacement, maximum stress, and plastic area volume were obtained after each mining step of each scheme.

4.1. Calculation Results of Six Schemes. The displacement, tensile stress, compressive stress, shear stress, and plastic zone results calculated for six schemes are shown below. The overall trends of the six scheme results were similar, and the displacement results are shown in Figure 4.

Based on the displacement change curve of each step in schemes 1-6 (Figure 4), the maximum displacement is $10.3 \mathrm{~cm}$ and occurs in step 19 of scheme 6 . In this step, the displacement increases significantly, and the following displacement remains stable. The maximum displacement of the roof does not occur at the current goaf but instead occurs in the roof of the large filling body. Therefore, the displacement of $10.3 \mathrm{~cm}$ in the roof of the large filling body will affect the whole project. The displacement of the roof in the 19th step is between 6-7 cm, which is also dangerous. During the actual engineering excavation, the area will be mined block by block. The displacement is expected to be less than $6 \mathrm{~cm}$, so it is necessary to use bolts and anchor mesh for support after excavation.

The plastic tensile failure zone curve under six schemes can be seen in Figure 5. The plastic tensile failure zone changes greatly after each step of mining. The maximum 


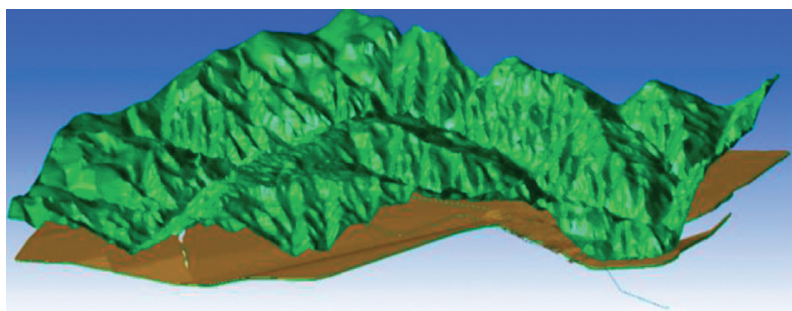

Figure 1: Geological model of Tiaoshuihe phosphate mine.

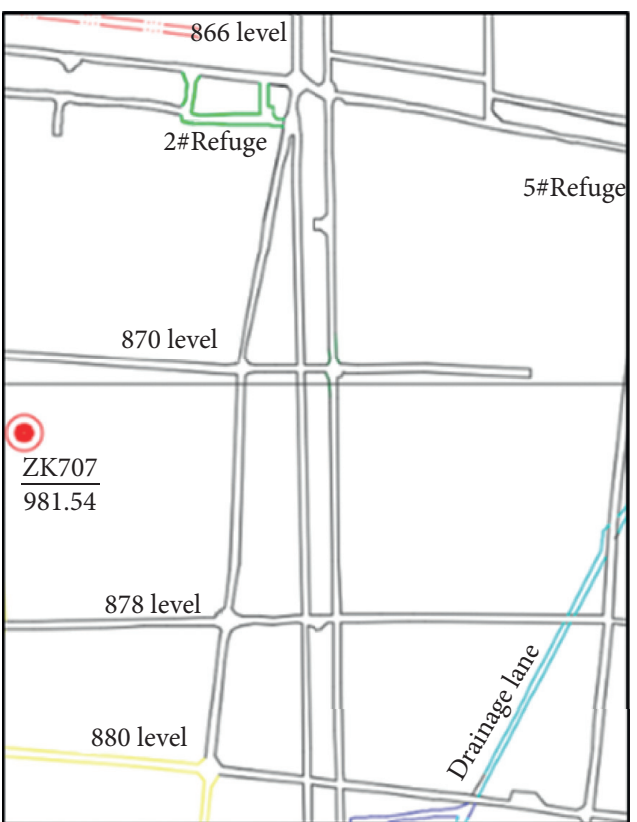

(a)

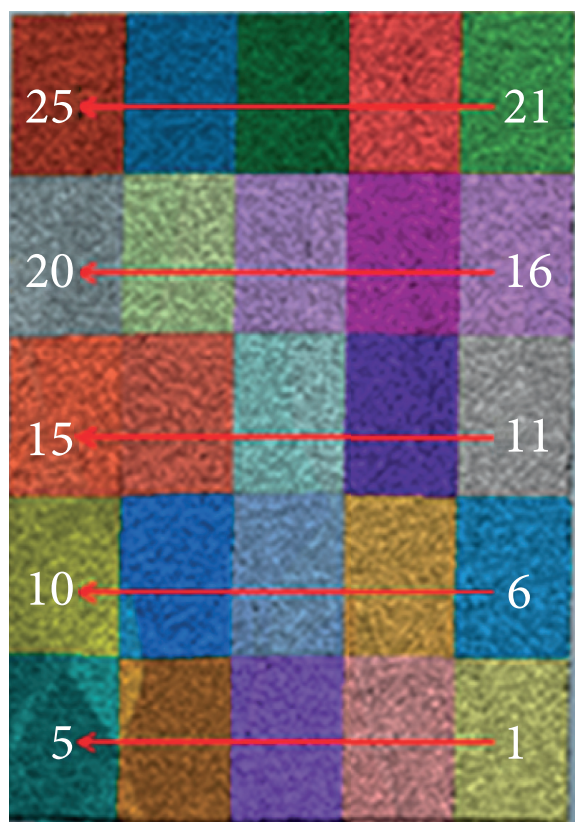

(b)

FIgURE 2: Optimization calculation model of mining sequence. (a) Geological map. (b) Block number.

value is found to be $380182 \mathrm{~m}^{3}$, which arises after step 25 of scheme 4 . The interface between the goaf and pillar exhibits high tensile stress, and the plastic tensile failure zone occurs mainly at the backfill. The maximum tensile plastic zone gradually expands with each step of mining for the first five steps and then expands more slowly after subsequent steps.

4.2. Analysis of the Maximum Values of Calculation Results Using Different Schemes. Changes in the displacement, stress, and plastic zone after each step of mining in each scheme are shown below. Table 2 highlights the maximum displacements, stresses, and the final plastic zone total volumes under different schemes. In Table 2, D represents the displacement, TS represents the tensile stress, CS represents the compressive stress, SS represents the shear stress, SF represents plastic shear failure zone volume, TF represents tensile failure zone, TSF represents the total volume of the plastic shear failure zone, and TTF represents the total volume of the plastic tensile failure zone.

Among the six schemes, the displacement of scheme 6 is the largest, while that of scheme 5 is the smallest throughout, with relatively stable displacement in every step. The tensile stress of scheme 6 is also the greatest, while those of schemes 5 and 2 are greater than those other schemes. Scheme 6 has the greatest compressive and shear stresses, followed by scheme 1. The plastic shear failure zone of scheme 2 is the largest, followed by scheme 4 . Scheme 2 produces the largest plastic zone of tensile failure, followed by scheme 3 . The total volume of the plastic shear failure zone in scheme 1 is the largest, while that of scheme 6 is the smallest. Scheme 2 produces the largest total volume of the plastic tensile failure zone, while scheme 5 produces the smallest.

The shear stress evolution trend is similar to the compressive stress. The maximum shear stress is $19.98 \mathrm{MPa}$ after step 13, produced at the joint of the long axis side roof, pillar, and filling body.

\section{Coordination of Mining Sequence and Production Capacity Target}

5.1. Calculation of the Production Capacity of the Tiaoshuihe Phosphate Mine. The current production plan at the Tiaoshuihe phosphate mine is 1 million $\mathrm{t} / \mathrm{a}$, and extracted ore is transported and exported by automobiles. Due to the high altitude of Zhangcunping Town, Yichang City, snow 


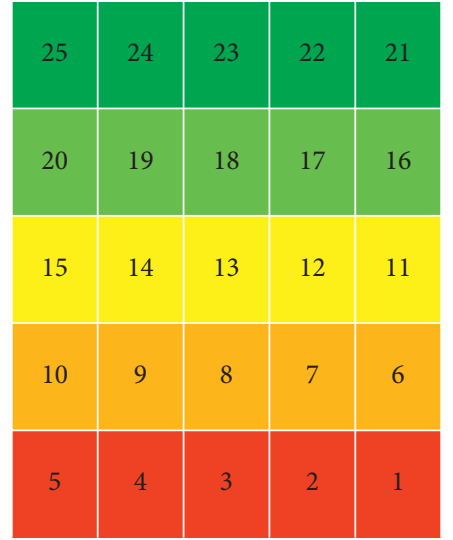

(a)

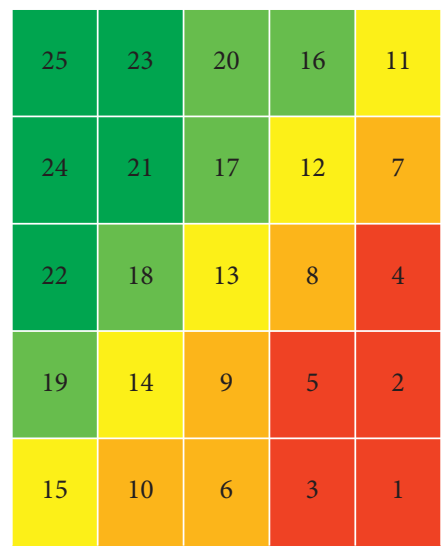

(d)

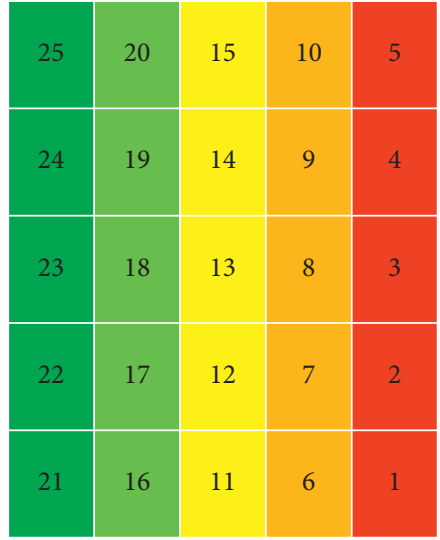

(b)

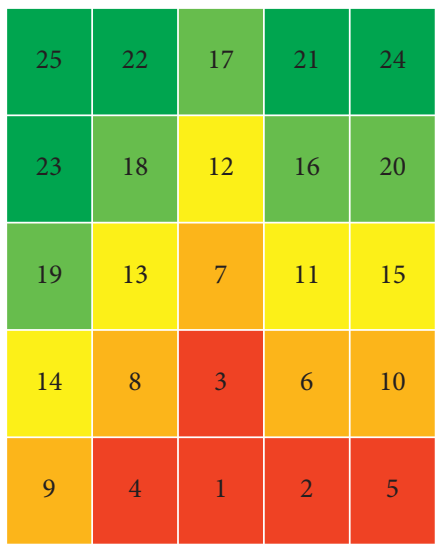

(e)

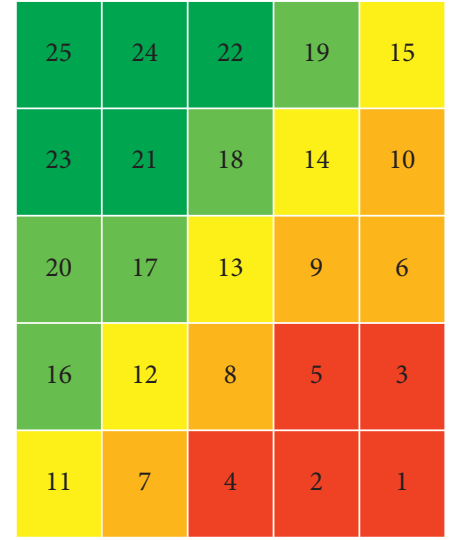

(c)

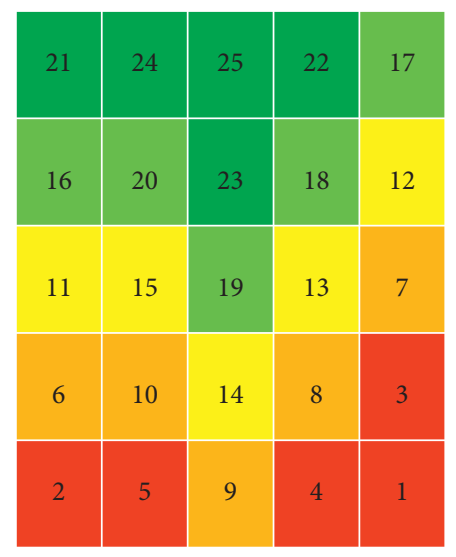

(f)

Figure 3: Mining sequence schemes 1-6. (a) Scheme 1. (b) Scheme 2. (c) Scheme 3. (d) Scheme 4. (e) Scheme 5. (f) Scheme 6.

TABLE 1: Mechanical parameters of the rock mass and backfill.

\begin{tabular}{lcccccc}
\hline Rock layer & $\rho\left(\mathrm{g} \cdot \mathrm{cm}^{-3}\right)$ & $K(\mathrm{GPa})$ & $G(\mathrm{GPa})$ & $\Phi\left(^{\circ}\right)$ & $C(\mathrm{MPa})$ & $T(\mathrm{MPa})$ \\
\hline Surrounding rock & 2.85 & 35.55 & 13.94 & 52.09 & 3.27 & 4.57 \\
Phosphate rock layer & 3.02 & 14.22 & 8.57 & 60.76 & 1.05 & 2.01 \\
Backfill & 2.20 & 2.86 & 2.61 & 38 & 1.40 & 0.60 \\
\hline
\end{tabular}

covering in winter shuts down transportation and production. Therefore, producing more than $4000 \mathrm{t} / \mathrm{d}$ is required to achieve the annual production target.

The ore grade stratification of the mine is relatively apparent. The upper layer is high-grade ore, and the lower layer is low-grade ore. This ore is mined in layers to reduce the mixing rate. Each operation can explore only half of the working face. The footage of one blasting is $2.83 \mathrm{~m}$, and the density of the phosphate rock is $3.021 \mathrm{~g} / \mathrm{cm}^{3}$. The production of one blasting in a single stope is $89.77 \mathrm{t}$.

Because the mining method of excavating alternate strips is adopted, each ore block can be divided into eight strips. Each ore block can have at most four strips being mined at the same time, so the single production capacity of each ore block is $359.08 \mathrm{t}$. A two-shift system is used at the Tiaoshuihe phosphate mine, where each shift completes one working procedure of drilling, blasting, and ore drawing and transportation. The daily production capacity of each ore block is $718.16 \mathrm{t}$. Therefore, according to the production target of $4000 \mathrm{t} / \mathrm{d}$, at least 5.6 ore blocks need to be mined at the same time to meet the production capacity requirements. However, a small part of the 870-898 m level in the eastern mining area has a good ore grade and does not need to be mined in layers. Therefore, to achieve the annual production, only five ore blocks need to be mined at the same time in this area.

Among the six different mining sequences, there are considerable differences in the distances between the five ore block centers. The discreteness of these five blocks has a significant influence on the cooperative use of equipment and operation cost in the mining process. The center of each group of five ore blocks mined at the same time is taken as the base point, and the sum of the distances from the center of each of the five ore blocks to the base point is called the center distance. Then, the center distance is used to measure the discreteness of five simultaneously mined ore blocks. The 


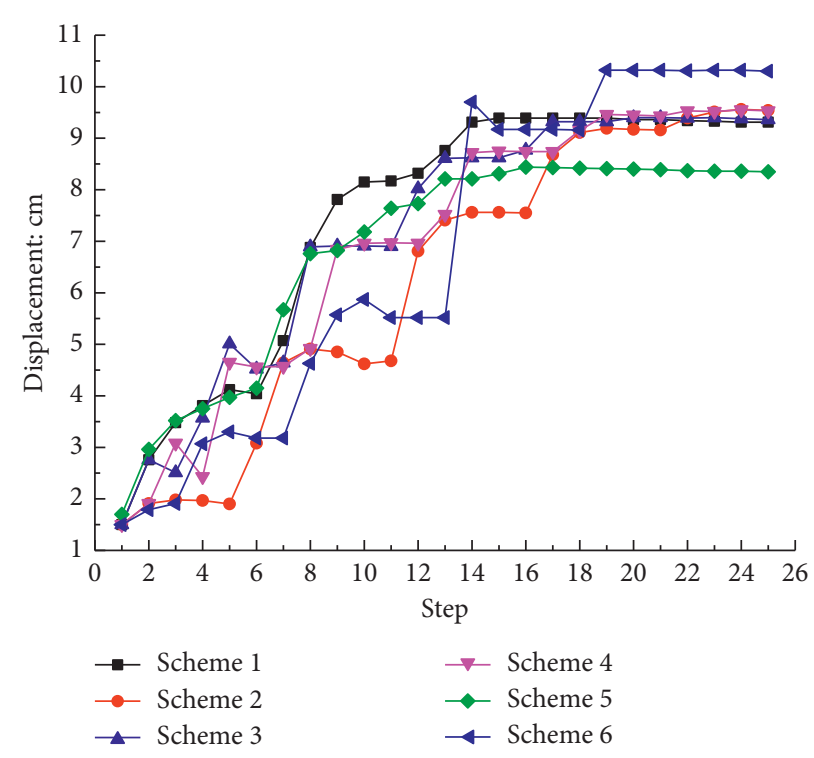

Figure 4: Displacement curve of schemes 1-6.

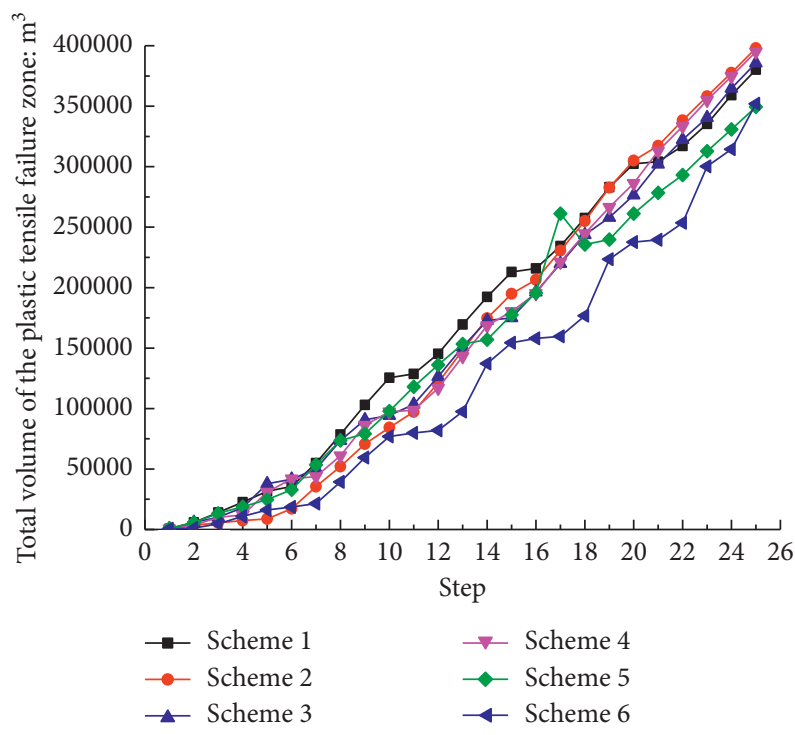

FIgUre 5: Plastic tensile failure zone of schemes 1-6.

TABLE 2: Calculation results of the six mining sequence schemes.

\begin{tabular}{|c|c|c|c|c|c|c|c|c|}
\hline Scheme & $\mathrm{D}(\mathrm{cm})$ & TS (MPa) & $\mathrm{CS}(\mathrm{MPa})$ & SS (MPa) & $\mathrm{SF}\left(\mathrm{m}^{3}\right)$ & $\mathrm{TF}\left(\mathrm{m}^{3}\right)$ & $\operatorname{TSF}\left(\mathrm{m}^{3}\right)$ & $\operatorname{TTF}\left(\mathrm{m}^{3}\right)$ \\
\hline 1 & 9.39 & 2.21 & 52.67 & 19.98 & 432578 & 264.57 & 10105900 & 380182 \\
\hline 2 & 9.56 & 2.24 & 50.32 & 18.35 & 621531 & 390.88 & 10024000 & 397980 \\
\hline 3 & 9.40 & 2.21 & 50.44 & 19.24 & 459187 & 375.76 & 10029400 & 385725 \\
\hline 4 & 9.55 & 2.23 & 50.33 & 18.26 & 525976 & 240.74 & 10034300 & 395019 \\
\hline 5 & 8.44 & 2.25 & 50.48 & 18.5 & 404996 & 272.14 & 9786510 & 349378 \\
\hline 6 & 10.3 & 2.39 & 56.71 & 21.19 & 473828 & 175.29 & 8794870 & 351962 \\
\hline
\end{tabular}

higher the discreteness, the lower the coordination degree of a given scheme.

Figure 6 shows the center distance calculation for the first group of ore blocks in scheme 1 . The distances from the five ore blocks to the base point are $0 \mathrm{~m}, 60 \mathrm{~m}, 60 \mathrm{~m}$,
$120 \mathrm{~m}$, and $120 \mathrm{~m}$. Therefore, the center distance of the first group in scheme 1 is $360 \mathrm{~m}$. Because the center distances of the five groups in scheme 1 are all $360 \mathrm{~m}$, the sum of the center distances of scheme 1 is $1800 \mathrm{~m}$. 


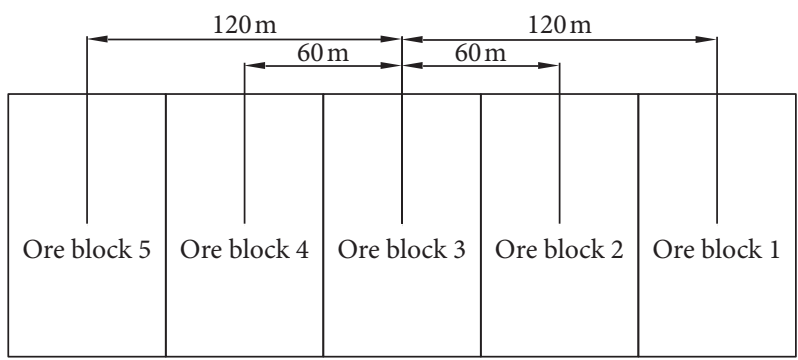

Figure 6: Calculating the center distance of the first step in scheme 1.

TABLE 3: Sum of the center distances of the six schemes.

\begin{tabular}{lcccccc}
\hline Scheme & 1 & 2 & 3 & 4 & 5 & 5 \\
\hline Sum of center distance $(\mathrm{m})$ & 1800 & 3000 & 2497.44 & 2672.64 & 2588.17 & 2588.17 \\
\hline
\end{tabular}

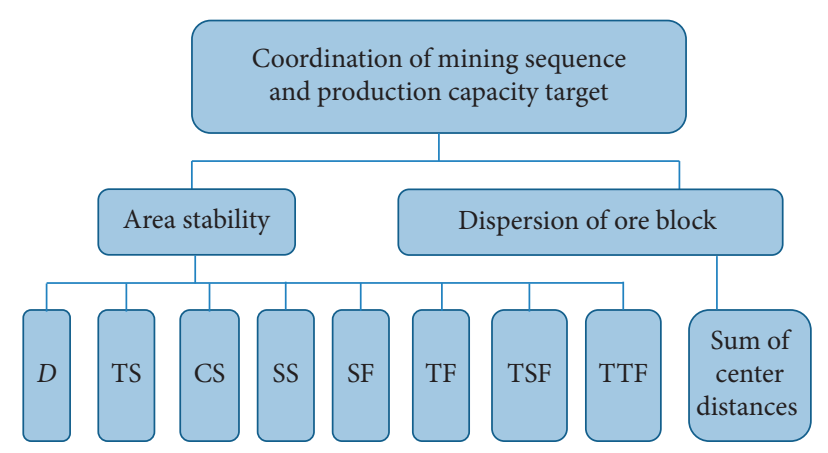

FIGURE 7: Collaborative model of mining sequence and production capacity target.

TABle 4: Score of the basic elements of the six schemes.

\begin{tabular}{lccccccccc}
\hline Scheme & $\mathrm{D}(\mathrm{cm})$ & $\mathrm{T}(\mathrm{MPa})$ & $\mathrm{C}(\mathrm{MPa})$ & $\mathrm{S}(\mathrm{MPa})$ & $\mathrm{SF}\left(\mathrm{m}^{3}\right)$ & $\mathrm{TF}\left(\mathrm{m}^{3}\right)$ & TSF $\left(\mathrm{m}^{3}\right)$ & TTF $\left(\mathrm{m}^{3}\right)$ & Dispersion \\
\hline 1 & 0.166 & 0.163 & 0.169 & 0.173 & 0.148 & 0.154 & 0.172 & 0.168 \\
2 & 0.169 & 0.166 & 0.162 & 0.159 & 0.213 & 0.227 & 0.171 & 0.176 \\
3 & 0.166 & 0.163 & 0.162 & 0.167 & 0.157 & 0.219 & 0.171 & 0.171 \\
4 & 0.169 & 0.165 & 0.162 & 0.158 & 0.180 & 0.140 & 0.171 & 0.175 \\
5 & 0.149 & 0.166 & 0.162 & 0.160 & 0.139 & 0.158 & 0.167 & 0.155 \\
6 & 0.182 & 0.177 & 0.182 & 0.183 & 0.162 & 0.102 & 0.150 & 0.156 \\
\hline
\end{tabular}

TABle 5: Coordination entropy values of basic elements of six schemes.

\begin{tabular}{lccccccccc}
\hline Scheme & $\mathrm{D}(\mathrm{cm})$ & $\mathrm{T}(\mathrm{MPa})$ & $\mathrm{C}(\mathrm{MPa})$ & $\mathrm{S}(\mathrm{MPa})$ & $\mathrm{SF}\left(\mathrm{m}^{3}\right)$ & $\mathrm{TF}\left(\mathrm{m}^{3}\right)$ & TSF $\left(\mathrm{m}^{3}\right)$ & TTF $\left(\mathrm{m}^{3}\right)$ & Dispersion \\
\hline 1 & 0.298 & 0.296 & 0.300 & 0.304 & 0.283 & 0.288 & 0.303 & 0.300 & 0.253 \\
2 & 0.300 & 0.298 & 0.295 & 0.292 & 0.329 & 0.337 & 0.302 & 0.306 & 0.321 \\
3 & 0.298 & 0.296 & 0.295 & 0.299 & 0.291 & 0.333 & 0.302 & 0.302 \\
4 & 0.300 & 0.297 & 0.295 & 0.292 & 0.309 & 0.275 & 0.302 & 0.305 \\
5 & 0.284 & 0.298 & 0.295 & 0.293 & 0.274 & 0.292 & 0.299 & 0.289 & 0.306 \\
6 & 0.310 & 0.306 & 0.310 & 0.311 & 0.295 & 0.233 & 0.285 & 0.290 \\
\hline
\end{tabular}

TABLe 6: Coordination degrees of the basic elements of six schemes.

\begin{tabular}{lccccccccc}
\hline Scheme & $\mathrm{D}(\mathrm{cm})$ & $\mathrm{T}(\mathrm{MPa})$ & $\mathrm{C}(\mathrm{MPa})$ & $\mathrm{S}(\mathrm{MPa})$ & $\mathrm{SF}\left(\mathrm{m}^{3}\right)$ & $\mathrm{TF}\left(\mathrm{m}^{3}\right)$ & TSF $\left(\mathrm{m}^{3}\right)$ & TTF $\left(\mathrm{m}^{3}\right)$ & Dispersion \\
\hline 1 & 0.039 & 0.034 & 0.031 & 0.024 & 0.141 & 0.145 & 0.000 & 0.021 \\
2 & 0.031 & 0.026 & 0.049 & 0.060 & 0.000 & 0.000 & 0.003 & 0.000 & 0.000 \\
3 & 0.038 & 0.034 & 0.049 & 0.039 & 0.116 & 0.013 & 0.003 & 0.013 \\
4 & 0.031 & 0.028 & 0.049 & 0.063 & 0.062 & 0.183 & 0.003 & 0.003 \\
5 & 0.085 & 0.026 & 0.049 & 0.057 & 0.166 & 0.135 & 0.014 & 0.056 & 0.047 \\
6 & 0.000 & 0.000 & 0.000 & 0.000 & 0.104 & 0.309 & 0.061 & 0.053 \\
\hline
\end{tabular}


TABLE 7: Coordination degree of six schemes.

\begin{tabular}{lcccccc}
\hline Scheme & 1 & 2 & 3 & 4 & 5 & 6 \\
\hline Coordination degree & 0.644 & 0.169 & 0.380 & 0.470 & 0.646 & 0.585 \\
\hline
\end{tabular}

The center distance for the other schemes is calculated similarly. The sums of the five groups of center distances for each scheme are shown in Table 3.

5.2. Calculation of Coordination Degree. According to previous calculation indicators, a collaborative model of mining sequence and production capacity target was established $[18,19]$, as shown in Figure 7.

The collaborative entropy method was used to calculate the coordination degree of various schemes. The value of entropy and the coordination degree of the system are inversely related. So, the larger the coordination entropy, the lower the coordination degree of the system. The smaller the coordination entropy is, the greater the coordination degree of the system is. According to equation (2), the basic elements in the collaboration model were evaluated and scored, and the calculation results are shown in Table 4 [20]:

$$
\theta=\frac{A_{i}}{\sum_{i=1}^{n} A_{i}}, \quad(i=1,2 \ldots, 6),
$$

where $\theta$ is the score of the basic element and $A_{i}$ is the value of the basic element.

Entropy value calculations of the basic elements follow equation (3) and are shown in Table 5.

$$
H(s)=-\theta \ln \theta
$$

where $H(s)$ is the value of coordination entropy.

Finally, according to equation (4), the coordination degrees of the basic elements of each scheme were calculated [17]:

$$
C_{i}=\frac{1-H_{i}}{H_{\max }}
$$

where $C_{i}$ is the coordination degree of the basic elements.

The calculated values of the coordination degrees of the basic elements are shown in Table 6 .

The coordination degree of each scheme can be obtained by summing the coordination degrees of the basic elements. The calculation results are shown in Table 7.

From the results of the coordination entropy method, the highest coordination degree, 0.646 , is found in scheme 5 . The second highest is calculated from scheme 1 , with a value of 0.644. Therefore, the use of a convex stepped shape in scheme 5 is the best mining scheme.

\section{Conclusions}

An accurate model of the 870-898 $\mathrm{m}$ level in the eastern mining area of the Tiaoshuihe phosphate mine was built, and the model grid was divided for mining sequence optimization. Command flows were written according to the six mining sequences. The results of the six schemes were calculated by using the Mohr-Coulomb constitutive model.
The annual production capacity of the mine was also calculated.

A collaborative model of the mining sequence and productivity target was established. Via the coordination entropy method, the final collaborative degree of the six schemes was determined. It was concluded that scheme 5 is the best, while scheme 1 is the second-best. Therefore, it was recommended that the $870-898 \mathrm{~m}$ level of the eastern mining area is mined using a convex stepped shape.

The theoretical research result of this study is that the idea of coordination is introduced into the process of mining sequence optimization and filling optimization. The basic parameters are brought into the coordination model by coordination entropy, and the coordination model includes all kinds of factors that affect the stability in the mining process. Economic indicators can also be taken into account in the future.

\section{Data Availability}

The data used to support the findings of this study are included within the article.

\section{Conflicts of Interest}

The authors declare that they have no conflicts of interest.

\section{Acknowledgments}

The support from National Key R\&D Program of China (2017YFC0602901) is sincerely appreciated.

\section{References}

[1] W. Pytel and B. Pałac-Walko, "Geomechanical safety assessment for transversely isotropic rock mass subjected to deep mining operations," Canadian Geotechnical Journal, vol. 52, no. 10, 2015.

[2] R. H. E. M. Koppelaar and H. P. Weikard, "Assessing phosphate rock depletion and phosphorus recycling options," Global Environmental Change, vol. 23, no. 6, pp. 1454-1466, 2013.

[3] T. Szwedzicki, "Pre- and post-failure ground behaviour: case studies of surface crown pillar collapse," International Journal of Rock Mechanics and Mining Sciences, vol. 36, no. 3, pp. 351-359, 1999.

[4] J. Lu, "Stability analysis of mined-out areas and optimization of residual ore stoping sequence at pumin iron mine," Master's Thesis, Wuhan University of Science and Technology, Wuhan, China, 2012.

[5] Y. Zou, "Study on the layout of deep mining access and optimization of mining sequence in jinchuan no. 2 mining area," Master's Thesis, Central South University, Changsha, China, 2007.

[6] X. Liu, C. Yang, and Z. Luo, "Numerical simulation optimization of mining sequence in deep mining," Journal of University of South China (Science and Technology), vol. 22, no. 4, pp. 15-21, 2008.

[7] P. Kang and X. Li, "Dynamic simulation of reasonable stoping sequence in middle section of panel in sanshandao gold mine," Mining and Metallurgical Engineering, vol. 30, no. 3, pp. 8-11, 2010. 
[8] Y. Ning and C. Liang, "Study on Optimization of mining sequence of two-step filling mining method," Mining Technology, vol. 14, no. 2, pp. 10-12, 2014.

[9] L. Zhang, J.-H. Hu, X.-L. Wang, and L. Zhao, "Optimization of stope structural parameters based on mathews stability graph probability model," Advances in Civil Engineering, vol. 2018, Article ID 1754328, 7 pages, 2018.

[10] J. Hu and L. Zhang, "Platform structure for intelligent underground mining system and its construction," Mining and Metallurgical Engineering, vol. 38, no. 6, pp. 1-5, 2018.

[11] Z. Yang, W. Li, X. Li, Q. Wang, and J. He, “Assessment of ecogeo-environment quality using multivariate data: a case study in a coal mining area of Western China," Ecological Indicator, vol. 12, no. 107, pp. 1-13, Article ID 105651, 2019.

[12] G. Steiner, B. Geissler, I. Watson, and M. C. Mew, "Efficiency developments in phosphate rock mining over the last three decades," Resources, Conservation and Recycling, vol. 105, pp. 235-245, 2015.

[13] M. Shabanimashcool and C. C. Li, "Numerical modeling of longwall mining and stability analysis of the gates in a coal mine," International Journal of Rock Mechanics and Mining Sciences, vol. 51, pp. 24-34, 2012.

[14] D. J. Reddish, "Numerical and experimental studies on rock presplitting," Transaction of Nonferrous Metals Society of China (English Edition), vol. 8, no. 4, pp. 705-709, 1999.

[15] C. C. Mendoza, Experimental and numerical behaviour of deep foundations made up by anker alluvial type piles founded in a porous soil of federal district, $\mathrm{PhD}$ Thesis, University of Brasilia, Brasilia, Brazil, 2013.

[16] K. Liu, Y. Xue, and H. Zhou, "Study on 3D nonlinear viscoelastic -plastic creep constitutive model with parameter unsteady of soft rock based on improved Bingham model," Rock and Soil Mechanics, vol. 39, no. 11, pp. 4157-4164, 2018.

[17] M. S. P. Wan, J. R. Standing, D. M. Potts, and J. B. Burland, "Pore water pressure and total horizontal stress response to EPBM tunnelling in London Clay," Géotechnique, vol. 69, no. 5, pp. 434-457, 2019.

[18] Q. Chen, K. Zhou, D. Gu et al., "Synergetic mining and cavity synergetic utilization," China Mining Magazine, vol. 20, no. 12, pp. 77-80, 2011.

[19] H. Haken, A. Wunderlin, and S. Yigitbasi, An Introduction to Synergetics, Kluwer Academic Publishers, Amsterdam, Netherlands, 1995.

[20] Q. Chen, "Study on synergism of hidden danger resources mining and goafs treatment," Ph. D's Thesis, Central South University, Changsha, China, 2009. 